\title{
De Quervain's subacute thyroiditis presenting as a painless solitary thyroid nodule
}

\author{
T Bianda, C Schmid
}

\begin{abstract}
Summary
We describe a 39-year-old woman presenting with a painless solitary thyroid nodule, initially without signs suggesting thyroiditis. The serum level of thyrotropin was suppressed whereas those of thyroxine and triiodothyronine were normal. Fine needle aspiration cytology showed no signs of inflammation or malignancy. One week later, the patient felt pain and tenderness on her neck, and erythrocyte sedimentation rate and $\mathrm{C}$-reactive protein were markedly elevated. Thyroid scintigraphy showed a suppressed thyroid pertechnetate uptake. At that time, the diagnosis of subacute thyroiditis was made. Upon treatment with steroids the patient's symptoms as well as the thyroid nodule resolved. This case illustrates that subacute thyroiditis de Quervain may present as a solitary, painless nodule with suppressed thyrotropin and should therefore be considered in the differential diagnosis of such lesions.
\end{abstract}

Keywords: thyroiditis de Quervain; thyroid nodule

Subacute thyroiditis, also called de Quervain's thyroiditis, is the most common form of non-autoimmune thyroiditis, most probably of viral aetiology. Patients usually have a history of antecedent upper respiratory infection and suffer from neck pain, thyroid tenderness and systemic symptoms of inflammatory disease. ${ }^{1}$ Whereas cases with typical signs of thyroiditis de Quervain may pose little difficulty, sometimes the diagnosis may be less clear, particularly when the presenting symptom is a painless, solitary thyroid nodule. The diagnosis of this variant form of subacute thyroiditis can cause considerable difficulty. We describe a patient initially showing a single, painless, thyroid nodule without the characteristic clinical features suggesting subacute thyroiditis.

Division of

Endocrinology and

Diabetes, Department

of Internal Medicine,

University Hospital,

CH-8091 Zürich,

Switzerland

T Bianda

C Schmid

Accepted 23 April 1998 tations. There was no history of fever, malaise, neck pain, antecedent upper respiratory infec- tion, drug or iodine exposure, or pregnancy. Her sister had Graves' disease. Physical examination showed a regular heart rate of 72 beats/ min, a blood pressure of $120 / 85 \mathrm{mmHg}$, an axilla temperature of $36.8^{\circ} \mathrm{C}$, no tremor and unremarkable reflexes. There were no signs of ophthalmopathy or dermopathy. We found a painless nodule in the right lobe of the thyroid gland with a diameter of $2 \times 2 \mathrm{~cm}$ without lymphadenopathy. Serum thyrotropin (TSH) was low $(<0.05 \mathrm{mU} / \mathrm{l})$, free thyroxine $\left(\mathrm{fT}_{4}\right)$ was 17 $\mathrm{pmol} / 1$ (normal range 8.5-19) and total triiodothyronine $\left(\mathrm{T}_{3}\right)$ was $2.6 \mathrm{nmol} / 1(0.9-2.8)$. TSH-receptor and antimicrosomal antibodies could not be detected. Thyroid sonography confirmed the presence of an inhomogenous, solid nodule in the right lobe without cystic lesions. Needle aspiration cytology from the nodule showed cell-rich material consisting of clusters of thyrocytes without multinucleated giant cells.

A few days later, the patient complained for the first time about pain in the thyroid gland which radiated to both ears and was aggravated by turning the head. Physical examination now showed a tender nodule in the left lobe of the thyroid (diameter $3 \times 2 \mathrm{~cm}$ ), whereas the nodule in the right lobe was no longer palpable. At this time, the laboratory tests showed increased erythrocyte sedimentation rate (ESR; $80 \mathrm{~mm} / \mathrm{h}$ ), C-reactive protein (CRP; 68 $\mathrm{mg} / \mathrm{l})$ and total $\mathrm{T}_{3}(3.1 \mathrm{nmol} / \mathrm{l})$, normal $\mathrm{fT}_{4}$ (17.4 pmol/l) and decreased TSH $(<0.05$ $\mathrm{mU} / \mathrm{l})$. Thyroid scintigraphy with $[99 \mathrm{~m}] \mathrm{Tc}$ pertechnetate revealed no tracer uptake. Nonsteroidal anti-inflammatory drugs were without convincing effects after treatment for several days but prednisone $(50 \mathrm{mg} /$ day $)$ therapy resulted in a prompt resolution of pain within 12 hours.

During the following week, the patient completely recovered, and no thyroid nodule could be detected by palpation; ESR $(18 \mathrm{~mm} / \mathrm{h})$ and CRP ( $4 \mathrm{mg} / \mathrm{l}$ ) returned to normal; serum $\mathrm{T}_{3}$ was $2.1 \mathrm{nmol} / 1, \mathrm{fT}_{4} 20.4 \mathrm{pmol} / 1$ and $\mathrm{TSH}<$ $0.05 \mathrm{mU} / \mathrm{l}$. Five weeks later, the patient, then receiving prednisone $20 \mathrm{mg} /$ day, remained asymptomatic; ESR was $3 \mathrm{~mm} / \mathrm{h}, \mathrm{CRP}<3$ $\mathrm{mg} / \mathrm{l}, \mathrm{T}_{3} 1.2 \mathrm{nmol} / 1, \mathrm{fT}_{4} 10.7 \mathrm{pmol} / \mathrm{l}$, and TSH had risen to $5.57 \mathrm{mU} / 1$. The patient presented after a further 6 weeks in good health. She had regained $1 \mathrm{~kg}$ of body weight, and neither palpation nor ultrasound showed a thyroid nodule. ESR was $5 \mathrm{~mm} / \mathrm{h}, \mathrm{fT}_{4} 11.2 \mathrm{pmol} / 1$, and TSH $6.22 \mathrm{mU} / 1$. 


\section{Discussion}

Patients with de Quervain's subacute thyroiditis may present with a typical neck pain radiating to the ears, jaws and throat, thyroid tenderness and systemic symptoms and signs of inflammatory disease, such as fever, malaise, fatigue and anorexia, with or without thyrotoxicosis. ${ }^{2}$ Hyperthyroidism results from destruction of the thyroid parenchyma with release of stored hormone. If there are symptoms of thyrotoxicosis, they are mild and transient, ${ }^{3}$ and may be followed by transient hypothyroidism. On physical examination the patient often appears acutely ill at presentation and the thyroid is tender and diffusely enlarged. The most important laboratory test suggesting subacute thyroiditis is an increased ESR (usually greater than $50 \mathrm{~mm} / \mathrm{h}$ ). Although it is often overlooked and misdiagnosed as pharyngitis, ${ }^{4}$ the diagnosis of thyroiditis de Quervain can be readily considered when patients present with the typical clinical picture. Depending on the physician's attitude and local availability, fine needle aspiration cytology, ultrasound or scintigraphy may support the diagnosis, in addition to the clinical course. Early recognition and diagnosis are necessary for appropriate management of affected patients.

On the other hand, the disorder can present with puzzling findings ${ }^{5-7}$ and can escape early recognition. Our patient presented with a solitary, painless nodule but neither history nor the initial clinical findings suggested an inflammatory disease. Therefore, the initial work-up included a laboratory check of thyroid function, an ultrasound examination of the neck and fine needle aspiration cytology of the nod-

1 Lazarus JH. Silent thyroiditis and subacute thyroiditis. In: Braverman LE, Utiger RD, eds. The thyroid. Philadelphia: Lippincott-Raven, 1996; pp 577-91.

2 Greene JN. Subacute thyroiditis. Am f Med 1971;51:97108.

3 Volpé R, Johnston MW, Huber N. Thyroid function in subacute thyroiditis. $\mathcal{F}$ Clin Endocrinol Metab 1958;18:6578.

4 Volpé R, Johnston MW. Subacute thyroiditis - a disease commonly mistaken for pharyngitis. Can Med Assoc $\mathcal{F} 1957$; 77:297-307.

\section{Learning points}

- neck pain radiating to the ears, thyroid tenderness, systemic symptoms including fever and malaise, and mild signs of hyperthyroidism are characteristic features of subacute thyroiditis

- a detailed history and clinical course may assist diagnosis in patients with an unusual presentation of thyroid disease

- subacute thyroiditis may present atypically with a solitary, painless thyroid nodule and should be considered in the differential diagnosis of such lesions

- steroid treatment leads to rapid resolution of nodular disease and inflammation

ule. These tests turned out to be nondiagnostic; a toxic adenoma was suspected. The clinical course and subsequent findings (neck pain, high ESR, low thyroid tracer uptake and good response to steroids) allowed us to consider a diagnosis of subacute thyroiditis as a cause of the nodule. Despite the fact that subacute thyroiditis appeared as a focal condition in our patient, tissue damage was sufficient to cause hormone release, resulting in suppressed TSH secretion and thyroid tracer uptake. ${ }^{8}$ The diagnosis of subacute thyroiditis de Quervain in this patient was delayed by the initial presentation without pain and signs of inflammation, although the first interview revealed clinical symptoms of thyrotoxicosis.

In conclusion, this case illustrates that subacute thyroiditis should also be considered in the differential diagnosis of a solitary, painless thyroid nodule with suppressed TSH.

5 Piazza I, Girardi A. Painless giant cell thyroiditis. Postgrad Med f 1989;65:580-1.

6 Bartels PC, Boer RO. Subacute thyroiditis presenting as a painless cold nodule. $\mathcal{F}$ Nucl Med 1987;28:1488-90.

7 Stonebridge PA. Occult subacute thyroiditis with unusual features. Lancet 1985;ii:727.

8 Hamburger JI, Kadian G, Rossin HW. Subacute thyroiditis evolution depicted by serial ${ }^{131}$ I-scintigrams. $f \mathrm{Nucl} \mathrm{Med}$ 1965;6:560-5. 